\title{
Seroprevalence of HBV and HCV among Healthy Blood Donors in a Tertiary Care Hospital of Northeast India: a 5-year Retrospective Study
}

\author{
Ritapa Ghosh ${ }^{1,2} *$ and Naba Kumar Hazarika ${ }^{2,3}$ \\ ${ }^{1}$ Vadodara Institute of Neurological Sciences, Vadodara 390007, Gujarat, India \\ ${ }^{2}$ Department of Microbiology, Gauhati Medical College and Hospital, \\ Guwahati 781032, Assam, India \\ ${ }^{3}$ Lab Operations, HLL Hindlabs Diagnostic Centres, Assam, India \\ *Corresponding author
}

\begin{tabular}{|c|c|}
\hline & A B S T R A C T \\
\hline & \multirow{6}{*}{$\begin{array}{l}\text { Presence of hepatitis B virus (HBV) and hepatitis C virus (HCV) in blood donors poses a } \\
\text { risk of transmission through blood transfusion. Chronic HBV and HCV infections put } \\
\text { people at high risk of diseases with high morbidity and mortality. We wanted to estimate } \\
\text { the seroprevalence of these infections in Northeast India by undertaking a study on the } \\
\text { healthy blood donors. In a retrospective study we reviewed the records of blood donors } \\
\text { from } 2009 \text { to } 2013 \text {. The donors were screened for HBsAg by MICROSCREEN ELISA } \\
\text { TEST KIT, Span Diagnostic Ltd and for anti-HCV by SD HCV ELISA 3.0, SD Bio } \\
\text { Standard Diagnostics Pvt. Ltd respectively. A total of } 136,116 \text { donations were received, } \\
\text { comprising of } 60.92 \% \text { voluntary donors and } 39.07 \% \text { replacement donors. } 94.08 \% \text { were } \\
\text { males and 5.32\% were females. The overall prevalence of HBsAg and anti-HCV positive } \\
\text { blood donors was } 0.77 \% \text { and } 0.37 \% \text { respectively. The prevalence rates were higher in the } \\
\text { replacement donors compared to the voluntary donors (p }<0.0001) \text {. There was decreasing } \\
\text { trend in the yearly rates of seroprevalence. This study gives a crude estimate of the } \\
\text { prevalence of HBV and HCV infections in the apparently healthy population of Northeast } \\
\text { India. }\end{array}$} \\
\hline & \\
\hline $\begin{array}{l}\text { Hepatitis B, } \\
\text { Hepatitis C, Blood } \\
\text { donors, HBsAg, } \\
\text { Anti-HCV }\end{array}$ & \\
\hline Article Info & \\
\hline $\begin{array}{l}\text { Accepted: } \\
\text { 06 June } 2018 \\
\text { Available Online: } \\
\text { 10 July } 2018\end{array}$ & \\
\hline & \\
\hline
\end{tabular}

\section{Introduction}

Hepatitis B and Hepatitis C are issues of global importance. Chronic HBV and HCV infections put people at high risk of fatality from liver cirrhosis and cancer. Laboratory diagnosis of $\mathrm{HBV}$ infection focuses on the detection of HBsAg. HCV infection is diagnosed by screening for anti-HCV. It is confirmed by detection of HCVRNA. The
World Health Organization (WHO) recommends that all blood donations are tested for HBsAg and anti-HCV to avoid accidental transmission. An estimated 257 million and 71 million people are living with HBV infection and chronic HCV infection, respectively. In the Indian subcontinent, an estimated $2-5 \%$ of the general population is chronically infected with HBV (WHO Hep B fact sheet, 2017; WHO Hep C fact sheet,2017).Based on few population-based 
studies, the prevalence of $\mathrm{HCV}$ infection in India is $0.09-2.02 \%$ (Mukhopadhyaya et al., 2008). In this study we attempt to estimate the prevalence of $\mathrm{HBV}$ and $\mathrm{HCV}$ infection in northeast India by a retrospective study of healthy blood donors.

\section{Materials and Methods}

This study was conducted by the Microbiology Department of Gauhati Medical College and Hospital, Guwahati, Assam. We reviewed the records of healthy blood donors (age group 18 - 60 years) in the model blood bank of our hospital retrospectively from January 2009 to December 2013.

This blood bank caters to the need of most of the patients of the districts of lower Assam. The donors were selected by trained personnel after completing a standard questionnaire and thorough physical examination. They were grouped into two types: 1. replacement donors (family members or friends of the patients) and 2. Voluntary donors (people who donate blood in camps or who donate blood without expecting any favour).

The donors were screened for $\mathrm{HBsAg}$ by MICROSCREEN ELISA TEST KIT, Span Diagnostic Ltd. and for anti-HCV by SD HCV ELISA 3.0, SD Bio Standard Diagnostics Pvt. Ltd., respectively. Both these kits are licensed for the use in blood banks in India (blood bank guidelines, CDSCO).In a study assessing the performance characteristics of various kits for Hepatitis B and C, the kits by J. Mitra and Co Pvt. Ltd. had 100\% sensitivity and 100\% specificity and the kits by SPAN Diagnostic Ltd., had $100 \%$ sensitivity and $98.7 \%$ specificity (Maity et al., 2012).

The prevalence was calculated based on the number of donations tested and number of donations with positive results in screening tests. Comparisons of prevalence rates in voluntary and replacement donors were carried out using Chi-square test. A significance criterion of $p \leq 0.05$ was used in the analysis.

\section{Results and Discussion}

There were 136,116 healthy blood donors, comprising of $128,064(94.08 \%)$ males and $8052(5.92 \%)$ females. There were 82,929 $(60.92 \%)$ voluntary donors and 53,187 $(39.07 \%)$ replacement donors (Figure 1). HBsAg was detected in 1049 (0.77\%) donors. Anti-HCV was detected in $504(0.37 \%)$ donors (Table 1).

The prevalence rates of $\mathrm{HBV}$ and $\mathrm{HCV}$ were significantly higher in the replacement donors (Figures 2 and 3). There was a decreasing trend in the prevalence rates of these infections (Figure 4).

Due to non-feasibility of carrying out large scale population based studies, several authors have tried to estimate the prevalence of HBV and $\mathrm{HCV}$ infections in the population by carrying out studies in the healthy blood donors. As WHO mandates checking of HBV and $\mathrm{HCV}$ infections in donated blood products prior to transfusion, this is a practical but very crude method of estimating the prevalence. We carried out this retrospective study because of lack of such prevalence studies in this part of northeast India.

We found a lower prevalence of $\mathrm{HBV}$ and $\mathrm{HCV}$ infections in healthy blood donors than those reported in previous comparative studies from other parts of India (Sonwane et al., 2003; Arora et al., 2010; Meena et al., 2011). Similarly, two studies fromother parts of northeast India showed lower prevalence rates of these infections in healthy blood donors (Dowerah S et al., 2017; Rahman S et al., 2016) (Table 2). 
Table.1 Year wise prevalence of HBsAg positive and anti-HCV positive blood donors

\begin{tabular}{|l|c|c|c|c|c|}
\hline Year & \multirow{2}{*}{ Donors } & \multicolumn{2}{|c|}{ HBsAg } & \multicolumn{2}{c|}{ Anti-HCV } \\
\hline & & $\mathrm{n}(\%)$ & $95 \% \mathrm{CI}$ & $\mathrm{n}(\%)$ & $95 \%$ CI \\
\hline $\mathbf{2 0 0 9}$ & 24624 & $264(1.07)$ & $(0.94,1.20)$ & $279(1.13)$ & $(1.00,1.26)$ \\
\hline $\mathbf{2 0 1 0}$ & 24223 & $208(0.86)$ & $(0.74,0.98)$ & $80(0.33)$ & $(0.26,0.40)$ \\
\hline $\mathbf{2 0 1 1}$ & 28242 & $181(0.64)$ & $(0.55,0.73)$ & $64(0.23)$ & $(0.18,0.28)$ \\
\hline $\mathbf{2 0 1 2}$ & 29409 & $184(0.62)$ & $(0.53,0.71)$ & $37(0.13)$ & $(0.09,0.17)$ \\
\hline $\mathbf{2 0 1 3}$ & 29618 & $212(0.71)$ & $(0.61,0.81)$ & $44(0.15)$ & $(0.11 .0 .19)$ \\
\hline Overall & 136116 & $1049(0.77)$ & $(0.72,0.82)$ & $504(0.37)$ & $(0.34,0.40)$ \\
\hline
\end{tabular}

Table.2 Comparative studies on the seroprevalence of HBV and HCV in blood donors

\begin{tabular}{|l|l|c|c|c|}
\hline Study & Place & Year & $\begin{array}{c}\text { HBsAg } \\
(\mathbf{\%})\end{array}$ & $\begin{array}{c}\text { Anti-HCV } \\
(\mathbf{\%})\end{array}$ \\
\hline Sonwane BR et al., 2003 & Ambajogai, Maharashtra & $1996-2001$ & 4.07 & - \\
\hline Arora D et al., 2010 & Hisar, Haryana & $2002-2006$ & 1.70 & 1.00 \\
\hline Meena M et al., 2011 & New Delhi, Delhi & $2005-2009$ & 1.43 & 0.57 \\
\hline Present study & Guwahati, Assam & $2009-2013$ & 0.77 & 0.37 \\
\hline Dowerah S et al., 2017 & Dibrugarh, Assam & $2012-2014$ & 0.39 & 0.10 \\
\hline Rahman S et al., 2016 & Jorhat, Assam & $2013-2016$ & 0.57 & 0.42 \\
\hline
\end{tabular}

Figure.1 Type of blood donors in the study

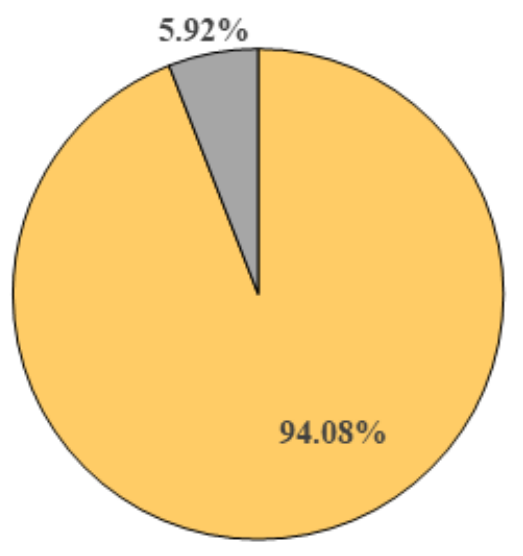

$\square$ Males $\square$ Females

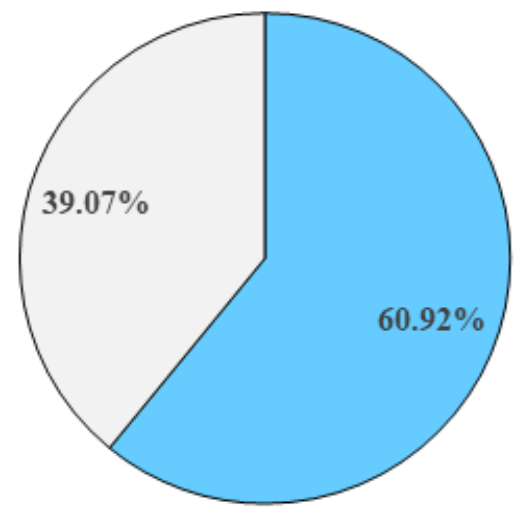

$\square$ Voluntary $\square$ Replacement 
Figure.2 Seroprevalence of HBV in relation to donor type

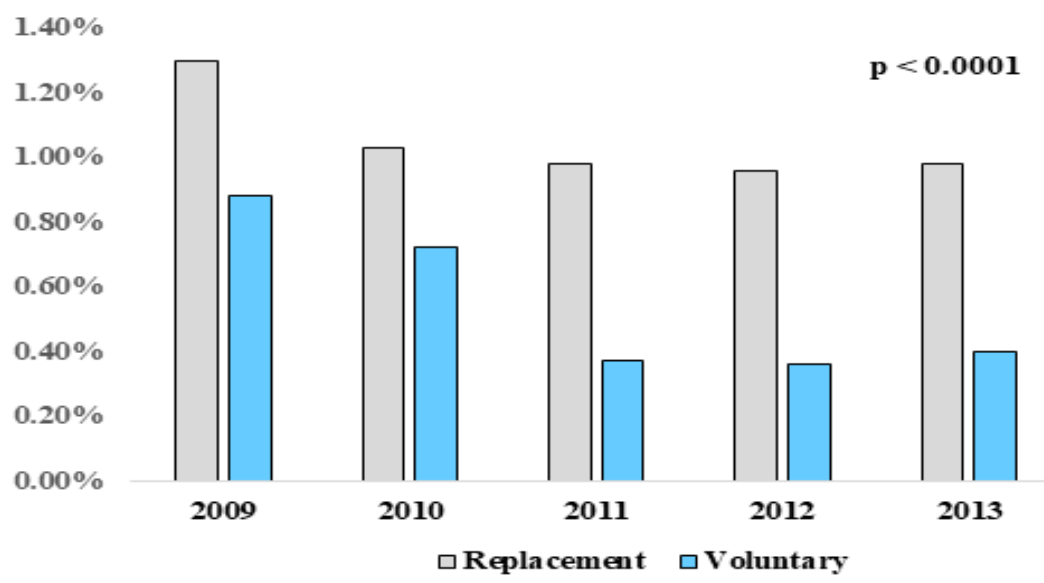

Figure.3 Seroprevalence of HCV in relation to donor type

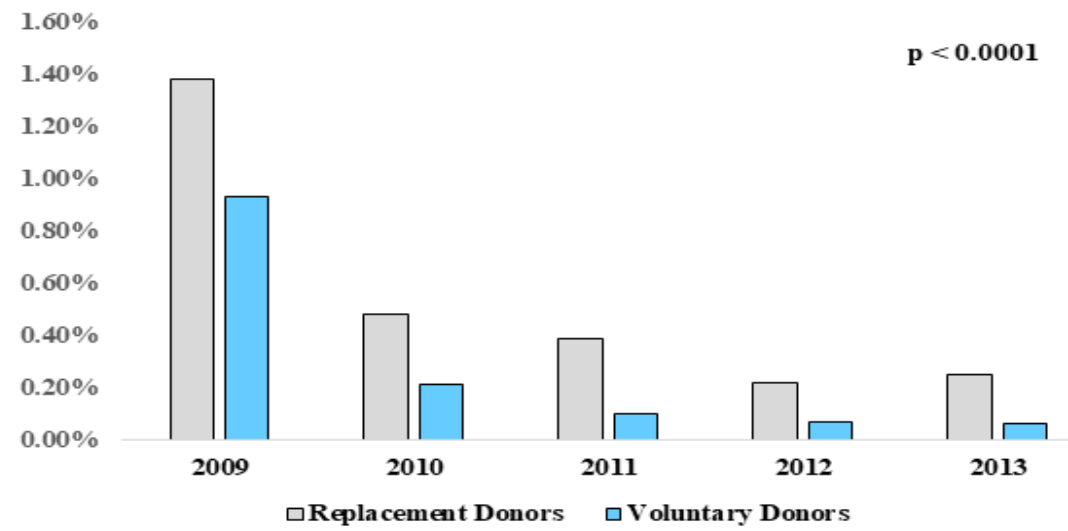

Figure.4 Trend in seroprevalence of $\mathrm{HBV}$ and $\mathrm{HCV}$ in blood donors

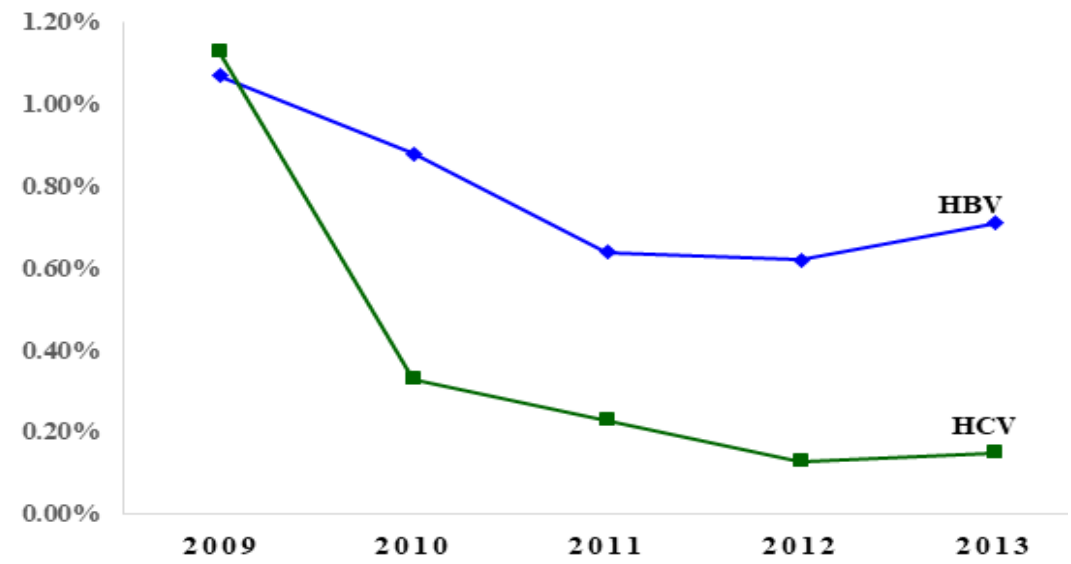


In the present study found that the prevalence rates of $\mathrm{HBV}$ and $\mathrm{HCV}$ infections were significantly high in replacement donors compared to voluntary donors. This has also been observed in previous studies and could be due to several factors such as concealing high risk behaviours and paid donors posing as relatives (Dowerah et al., 2017; Rahman et al., 2016; Makroo et al., 2015; Fulzele et al., 2017). There was no significant difference in the prevalence rates of $\mathrm{HBV}$ and $\mathrm{HCV}$ infections in male and female blood donors. Females formed a very small proportion of donors probably due to higher prevalence of anaemia in women.

The present investigation noted a decreasing trend in the prevalence rates of $\mathrm{HBV}$ and $\mathrm{HCV}$ infections in the donors. Though replacement donors comprised a large proportion of blood donors, there was a rise in proportion of voluntary blood donors in camps from $3.31 \%$ in 2009 to $10.08 \%$ in 2013. This rise in voluntary blood donation in camps could partly account for the decreasing trend of $\mathrm{HBV}$ and $\mathrm{HCV}$ infections in blood donors. Previously, some authors have found a consistent decreasing trend of $\mathrm{HBV}$ infection and slightly increasing trend in $\mathrm{HCV}$ infection in blood donors (Dowerah et al., 2017; Rahman et al., 2016; Makroo et al., 2015). Introduction of hepatitis B vaccine in national immunization programmes, educational programmes and availability of resources to diagnose hepatitis in health centre may partly account for the decreasing trend.

\section{Limitations}

Study on healthy blood donors gives a very crude estimate of the prevalence of HBV and $\mathrm{HCV}$ infections in the population. People who are symptomatic are unlikely to donate blood and many with risk factors are screened out by the blood bank personnel. Females are under-represented as blood donors in the study. Serological markers other than $\mathrm{HBsAg}$ and anti-HCV have not been used. It is possible to have donors with occult HBV infection or few in window period, who lack detectable HBsAg but whose exposure to HBV infection is indicated by a positive antiHBc and HBV DNA (Dreier J1et al., 2004). Studies show high prevalence of $\mathrm{HBV}$ and $\mathrm{HCV}$ in high risk groups and closed communities from northeast India (Devi KS et al., 2004; Biswas et al., 2007; Phukan et $a l ., 2001)$. This study is therefore likely to underestimate the burden of HBV and HCV infections in the overall population.

In conclusion, the current infectious disease pattern and trends in donor population can help in planning of transfusion related health challenges in the future. Despite limitations, this study roughly gives an idea on the prevalence of $\mathrm{HBV}$ and $\mathrm{HCV}$ infections in apparently healthy population of northeast India. Encouraging female and voluntary blood donation may increase safer donor pool. There is need for improvement and implementation of strict donor selection and more sensitive screening tests to prevent inadvertent transmission of these infections.

\section{Acknowledgement}

The authors are grateful to the authorities of Gauhati Medical College and Hospital and its State of the Art Blood Bank for allowing them to access to and publication of the record and data thereof.

\section{References}

Arora D, Arora B, et al., Seroprevalence of HIV, HBV, HCV and syphilis in blood donors in Southern Haryana. Indian J Pathol. Microbiol. 2010 AprJun; 53 (2): 308-9

Biswas D, Borkakoty BJ, et al., 
Hyperendemic foci of hepatitis B infection in Arunachal Pradesh, India. J Assoc Physicians India. 2007 Oct; 55: 701-4.

Blood bank. Central Drugs Standard Control Organization. Guidelines for blood banks. Available from: http://cdsco.nic.in/html

Devi KS, Singh N B, et al., Seroprevalence of hepatitis $B$ virus and hepatitis $C$ virus among hepatic disorders and injecting drug users in Manipur - A preliminary report. Indian J Med Microbiol 2004; 22: 136-7.

Dowerah S, Sharma A, Thapa G. Seroprevalence of Hepatitis B and C among blood donors attending a State of the Art Model Blood Bank of North East India. Sch. J. App. Med. Sci., Aug 2017; 5 (8D): 3264-3267.

Dreier J1, Kröger M, Diekmann J, et al., Low-level viraemia of hepatitis B virus in an anti-HBc- and anti-HBspositive blood donor. Transfus Med. 2004; 14: 97-103.

Fulzele Parag Prabhakar, Yasmeen Khatib, Akanksha Gaajre, Richa Patel, Arsala Mulla, Surekha Khaire. Infectious disease screening and trends in blood donors in a hospital-based blood bank in Mumbai, Western India. International Journal of Contemporary Medical Research 2017; 4(2): 569572.

Maity S, Nandi S, Biswas S, et al., Performance and diagnostic usefulness of commercially available enzyme linked immunosorbent assay and rapid kits for detection of HIV, HBV and HCV in India. Virol J. 2012 Nov 26; 9: 290

Makroo RN, Hegde V, Chowdhry M, Bhatia A, Rosamma NL. Seroprevalence of infectious markers and their trends in blood donors in a hospital-based blood bank in north India. The Indian Journal of Medical Research. 2015;142(3):317-322.

Meena M, Jindal $\mathrm{T}$, et al., Prevalence of hepatitis $\mathrm{B}$ virus and hepatitis $\mathrm{C}$ virus among blood donors at a tertiary care hospital in India: a five-year study. Transfusion. 2011 Jan; 51(1):198-202.

Mukhopadhyaya A. Hepatitis C in India. J Biosci2008 Nov; 33: 465-473.

Phukan AC, Sharma SK, et al. HCV activity in an isolated community in north east India. Indian J Pathol Microbiol. 2001 Oct; 44(4):403-5.

Rahman S, Gogoi G. Seroprevalence of Hepatitis B and Hepatitis C virus infection among healthy blood donors in a tertiary care hospital: A retrospective study. Global Journal for Research Analysis. 2016 Mar; 5 (3): 326-328.

Sonwane BR, Birare SD, et al., Prevalence of seroreactivity among blood donors in rural population. Indian $\mathbf{J}$ of Med Sci 2003; 57: 405-407.

WHO Hep B fact sheet, July 2017.

WHO Hep C fact sheet, October 2017.

\section{How to cite this article:}

Ritapa Ghosh and Naba Kumar Hazarika. 2018. Seroprevalence of HBV and HCV among Healthy Blood Donors in a Tertiary Care Hospital of Northeast India: a 5-year Retrospective Study. Int.J.Curr.Microbiol.App.Sci. 7(07): 531-536. doi: https://doi.org/10.20546/ijcmas.2018.707.065 